\section{O Centro de Documentação e Memória da Mogiana: Extensão Universitária e Gestão de Documentos Históricos do Período Cafeeiro}

\author{
The Centro de Documentação e Memória da Mogiana: \\ University Extension and Management of Historical \\ Documents of the Coffee Period
}

\section{RESUMO}

A documentação histórica do café, pertencente ao ciclo de produção cafeeira na região de Ribeirão Preto, ainda dispersa nos porões de fazendas ou centralizada em órgãos públicos, poderá agregar valores ao patrimônio cultural nacional. No entanto, o acesso a tais documentos é limitado principalmente pelo estado precário de conservação, armazenamento muitas vezes incorreto e, não raro, pelos meios de veiculação inadequados ao acesso informacional. Propusemos a implantação de um centro de documentação com funções determinadas, como: higienizar, conservar e digitalizar documentos que abordam a história regional do café. O projeto teve caráter de extensão e pesquisa universitária com envolvimento de alunos da Universidade de São Paulo, da Faculdade de Filosofia, Ciências e Letras de Ribeirão Preto, dos respectivos cursos: Física Médica, Psicologia e Ciência da Informação.

Palavras-chave: Centro de Documentação. Extensão. Pesquisa. Café.

\section{ABSTRACT}

The coffee historical documentation, belonging to the production coffee cycle in the Ribeirão Preto region, even in the basements of dispersed farms or centralized in public institutes, can add value to the national cultural heritage. However, access to such documents is limited mainly by the poor state of preservation, storage, often incorrect, and inappropriate means to access the information. We propose the establishment of a documentation center with the functions: to clean, to conserve and to scan documents that aproach the regional History of Coffee. The work had character of extension and university research involving students of the University of São Paulo, of Faculdade de Filosofia, Ciências e Letras, of the respective courses: Medical Physics, Psychology and Information Sciences.

Keywords: Documentation Center. Extension. Research. Coffee

\section{Silvia Maria do EsPírito SANTO, JEAM HAROLDO Oliveira Barbosa e Juliana Dal Ponte TIVERON}

Universidade de São Paulo. Faculdade de Filosofia, Ciências e Letras de Ribeirão Preto, São Paulo, Brasil 


\section{INTRODUÇÃO}

As confluências dos fatos no passado e a valorização, no presente, dos artefatos (materiais) e das significações históricas (imateriais) remetem às primeiras preocupações com a formação de um Museu Nacional, implantado por D. João VI em território brasileiro. Hoje, esta instituição é reconhecida como Museu Nacional da Universidade Federal do Rio de Janeiro, também denominado Museu da Quinta da Boa Vista. A antiga residência imperial foi transformada em instituição de memória. Os acontecimentos neste período reportam o Brasil emergente para a independência, baseado na economia de exportação da produção do café. O mundo rural cafeeiro já superava o ciclo açucareiro, tornando-se significativo na produção mundial, ainda mesmo no Império $[1,2]$.

As forças econômicas e políticas também são espelhamentos das variantes da produção agrária e, nas cidades modernas, da principiante industrialização. Tais forças solidificaram a ideia da constituição de uma identidade da nacionalidade representada em museus, arquivos e bibliotecas, ainda no século XIX. Mais recentemente, além das instituições tradicionais, configuraram-se os centros de documentação como instituições de memória [3], talvez já influenciados pela voraz intenção de organizar a memória e o conhecimento ainda no findar do século XIX.

Tais centros, idealizados como aqueles que seriam capazes de agregar as diversidades tecnológicas dos suportes das memórias científica e cultural, despertariam questões que envolveriam a memória e o patrimônio, que são comumente associados aos valores da cidade industrial. Ainda em desenvolvimento, a memória rural recebeu as primeiras iniciativas de preservação baseadas na produção da cana-de-açúcar, na primeira metade do século XX, no nordeste brasileiro, principalmente através da literatura.

Dessa forma, um centro de documentação se difere de arquivos, bibliotecas e museus por possuir uma natureza híbrida na constituição de suas coleções. As funções sociais das instituições de memória, engrandecidas pela diversidade do alcance do acesso documental, são: preservar, tratar e disseminar a documentação temática utilizando modernas tecnologias.

O campus da Universidade de São Paulo em Ribeirão Preto desenvolveu-se a partir de uma história de ocupação de uma antiga fazenda de café. Apesar do seu passado, não muito distante, pouco se conhece da região cafeeira do chamado antigo Oeste Paulista. Ainda que estejam presentes no meio acadêmico como tema de pesquisas históricas e científicas, o universo cultural da escravidão - dos proprietários portugueses, brasileiros e dos seus colonos imigrantes - é ainda pouco explorado.

O legado desse passado são artefatos, representativos dos maquinários mecânicos agrícolas, das edificações em tijolos cozidos, dos terreiros de café e, principalmente, dos processos remotos da produção do café - que transformou a vida do paulista, sendo todo este material registrado em documentos.

O presente artigo relata a experiência de extensão e pesquisa universitária [4] no processo de implantação de um centro de documentação referente à história regional do café. Embora no âmbito acadêmico, com características multidisciplinares, envolvam-se áreas diversas com práticas e discussões a respeito da preservação do passado, não 
trataremos da aplicação dos conceitos de conservação, prevenção e restauração envolvendo as tecnologias digitais no sentido da preservação. Para tanto, o relato salienta as questões do conhecimento das representações documentais históricas, articuladas às práticas e ao envolvimento multidisciplinar da pesquisa científica, realizada por alunos de diversas áreas da Universidade de São Paulo de Ribeirão Preto.

O trabalho promoveu pesquisa, planejamento e implantação no Centro de Documentação e Memória da Mogiana, entre 2011 e 2013. Neste sentido, o projeto envolveu, no total, 20 alunos de graduação e pós-graduação da Faculdade de Filosofia, Ciências e Letras de Ribeirão Preto (FFCLRP-USP), dos respectivos cursos: Física Médica, Psicologia e Ciência da Informação. A gestão do projeto foi realizada a partir do contrato entre empresa privada e a Fundação de Apoio às Ciências: Humanas, Exatas e Naturais - FAC - da FFCLRP.

\section{MATERIAIS E MÉTODOS}

\section{Colaboração entre Universidade e Iniciativa Privada}

Em caráter colaborativo entre setor privado e universidade, a empresa Rotunda Holding Ltda., com sede em São Paulo e proprietária da fazenda Santa Cecília*, firmou contrato com a Fundação de Apoio às Ciências: Humanas, Exatas e Naturais - FAC da Faculdade de Filosofia, Ciências e Letras da Universidade de São Paulo em Ribeirão Preto. Por parte da Universidade, as metas incluíam: fornecer pesquisa e práticas de preservação, planejamento para a compra de equipamentos, apoio técnico, treinamento e orientação para alunos (de iniciação científica e pós-graduação). $\mathrm{O}$ foco principal de aprendizagem no estágio e treinamento seria a obtenção de conhecimento técnico para aplicar as funções de higienização, digitalização e conservação preventiva aos documentos, além do desenvolvimento de extensão cultural na realização de oficinas, seminários e cursos. Por parte da empresa, foi garantido todo o financiamento do projeto, pagamento de ajuda de custo e de bolsas para os alunos.

As metas para implantação e organização do centro, com diretrizes firmadas em contratos e relatórios (anuais e trimestrais) para o desenvolvimento do projeto, foram registradas e supervisionadas em relatórios de atividades dos alunos bolsistas.

As atividades do Centro de Documentação tiveram início antes mesmo da inauguração do espaço físico, no dia 14 de abril de 2012 (Figuras 1 e 2). Neste dia, houve festividade com apresentação musical do grupo de alunos da escola de música, sob coordenação do professor da Faculdade de Filosofia, Ciências e Letras de Ribeirão

\footnotetext{
*A fazenda Santa Cecília, antiga fazenda Santa Carlota, foi propriedade da família Sampaio Moreira durante 103 anos, e é situada no município de Cajuru, estado de São Paulo, na rodovia 338, km 300 (coordenadas -21.346887, -47.256436). Fazenda Santa Cecília: Disponível em: <http://www.fazendasantacecilia.com.br>. Acesso em: 2 mai. 2012. O projeto foi coordenado pela Profa. Dra. Silvia Maria do Espírito Santo, do Departamento de Educação, Informação e Comunicação da FFCLRP - site: www.lacca. imagcom.org.
} 
Preto (FFCLRP-USP), Prof. Dr. Rubens Ricciardi, e palestra do Prof. Dr. Paulo Cesar M. Garcez, historiador e pesquisador do Museu Paulista, para a comunidade representativa da região. Estiveram presentes professores da FFCLRP, Unesp, Unicamp e USP, autoridades políticas de cidades da região de Ribeirão Preto, representantes de instituições culturais, imprensa, TV e cerca de 200 pessoas convidadas.

Os alunos bolsistas da USP (Figuras 1 e 2) monitoraram, para os convidados, as atividades em desenvolvimento e realizaram visitas em percurso na estação ferroviária Sampaio Moreira, da Companhia Mogiana, e em construções do complexo cafeeiro, passando por locais como: os terreiros de café, a tulha e a casa de máquinas para beneficiar e classificar os grãos de café. Os meios de comunicação (impressos e online) fizeram coberturas da inauguração com o intuito de noticiar a parceria entre universidade e iniciativa privada, além das atividades de pesquisa, cultura e extensão realizadas pelos alunos e professores.

Figura 1 - Fotos da inauguração do Centro de Documentação e Memória da Mogiana, no dia 14 de abril de 2012 (à esquerda). Professora orientadora, alunos e colaboradores da Universidade de São Paulo (à direita).

Figura 2 - Fotos da monitoria supervisionada ao complexo cafeeiro da fazenda Santa Cecília.
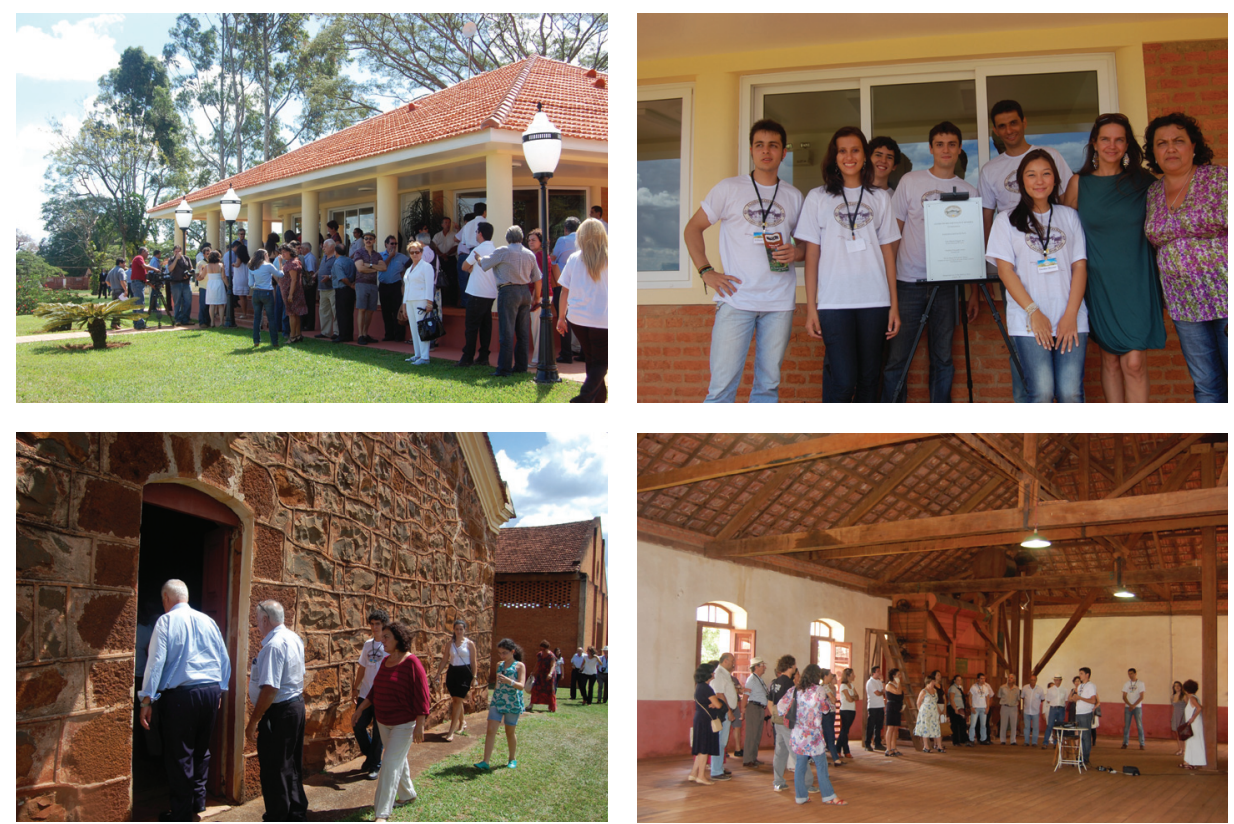

\section{Seleção e Adequações Físicas para o Centro}

A fazenda Santa Cecília - a qual teve sua origem nas frentes pioneiras do café, no nordeste paulista - possui elementos da riqueza arquitetônica e histórica (Figuras 3 e 4). Reúne cerca de 50 unidades, como casa grande, colônia, terreiro, casa de máquinas, tulha, administração, armazéns, clube, farmácia e laboratório com infraestrutura conservada ou adequada para uso definido agropecuário [5]. Para a implantação do Centro de Documentação foi necessária, primeiramente, a adequação de um prédio, selecionado entre todas as unidades disponíveis da fazenda. O prédio escolhido foi um lugar estratégico para facilitar a entrada e saída de documentos com segurança e, do ponto de vista geográfico, facilitar o acesso social. 

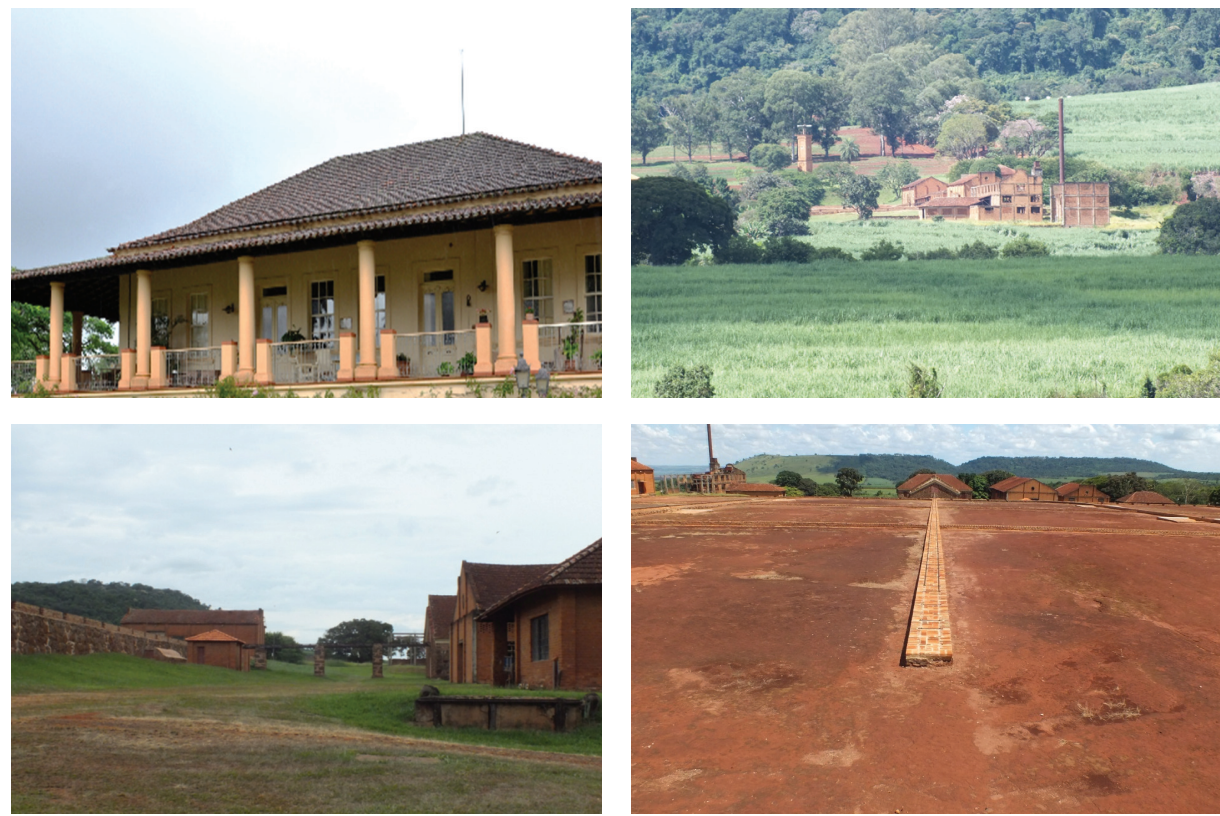

O acervo da fazenda possui livros manuscritos, textos de qualidade tipográfica em papel de fabricação nos séculos XIX e XX - cartas geográficas da época cafeeira e demais documentos referentes às famílias envolvidas na produção do café; administração de trabalhadores imigrantes, registros do plantio de outras culturas como arroz, feijão e milho, criação de gado vacum e cavalos, entre outras atividades agropecuárias.

O prédio que abriga a documentação histórica recebeu adequações ambientais internas, devidamente orientadas pelo arquiteto e preservacionista Prof. Dr. Marcos Tognon (Unicamp). Neste espaço, com vista panorâmica privilegiada, foram trocados os vitrôs por modernas janelas com vedação absoluta, sistema contra incêndio, ar condicionado, banheiro adaptado, laboratório destinado à conservação preventiva, sala de consulta e hall com armários individuais para visitantes.

Desta maneira, foram instalados os seguintes materiais e equipamentos usuais nas instituições que objetivam a preservação: materiais de escritório; computadores para consulta à internet e produção de textos; servidor de dados com acesso à rede de internet, com segurança de dados e endereço eletrônico para divulgação; equipamento de digitalização OpticBook $\mathrm{A}_{3} 00$ (com capacidade de digitalizar até folha $\mathrm{A}_{3}$ em apenas 2,4 segundos e função de reconhecimento de caracteres óticos); equipamentos de higienização: mesa restauradora com dimensões de $100 \mathrm{~cm}$ x $150 \mathrm{~cm}$, materiais simples de higienização, seladora, mesa de luz com dimensões de $100 \mathrm{~cm}$ x $150 \mathrm{~cm}$, aspirador de pó e materiais adequados para acondicionamento de documentos em papel.

\section{EQUIPE E CAPACITAÇÃO TÉCNICA}

A equipe foi composta por uma secretária contratada para o centro, 20 alunos do
Figura 3 - Fotos da fazenda Santa Cecília. Casa da sede da fazenda (à esquerda). Vista do complexo cafeeiro de longe (à direita).

Figura 4 - Imagens da fazenda Santa Cecília, no município de Cajuru, SP. Créditos: Prof. Dr. Marcos Tognon (Unicamp). 
curso de Ciência da Informação e Documentação, três alunos de pós-graduação em Psicologia, História e Física Médica, respectivamente, da FFCLRP-USP, e um aluno de Ciência da Computação da Universidade Paulista. Os alunos tiveram contratos regulares e produção de pesquisa com apresentação em eventos científicos nacionais e internacionais. Durante dois anos tiveram a oportunidade de exercer atividades voltadas para a pesquisa in loco, com leitura da documentação histórica e prática da conservação preventiva e digitalização.

O caminho, por via rural, exigia dos envolvidos o hábito de acordar ainda durante a madrugada e, assim, acompanhados de trabalhadores rurais, profissionais da educação e saúde públicas, tomavam um transporte de linha, ou condução coletiva, que os levava a pequenas cidades, sítios e fazendas. O trajeto de Ribeirão Preto à fazenda Santa Cecília é de $70 \mathrm{~km}$, percurso realizado pelos estudantes para estagiarem na antiga região cafeeira.

A capacitação técnica foi oferecida aos alunos e profissionais interessados, parte deles das instituições de memória de municípios vizinhos, durante 21 eventos. O público geral foi de 200 participantes, que tiveram a oportunidade de entrar em contato com tecnologias atuais, teorias e práticas através de oficinas, palestras e cursos ministrados por professores reconhecidos e responsáveis por importantes instituições brasileiras de conservação, acesso à informação, pesquisas históricas e culturais em modalidades diversas. A prática das oficinas foi realizada no próprio acervo do centro e na Faculdade de Filosofia, Ciências e Letras da USP de Ribeirão Preto.

\section{RESULTADOS}

\section{Atividades do Centro de Documentação}

O primeiro momento das atividades sobre o acervo da fazenda foi o reconhecimento dos documentos referentes ao cotidiano da fazenda. $\mathrm{O}$ segundo momento destinou o acervo ao tratamento de conservação preventiva (Figura 5). E, por último, foi realizada a digitalização de aproximadamente 20 mil documentos (Figuras 6 e 7).

\footnotetext{
Figura 5 - Higienização e tratamento de conservação do acervo da fazenda Santa Cecília.
}
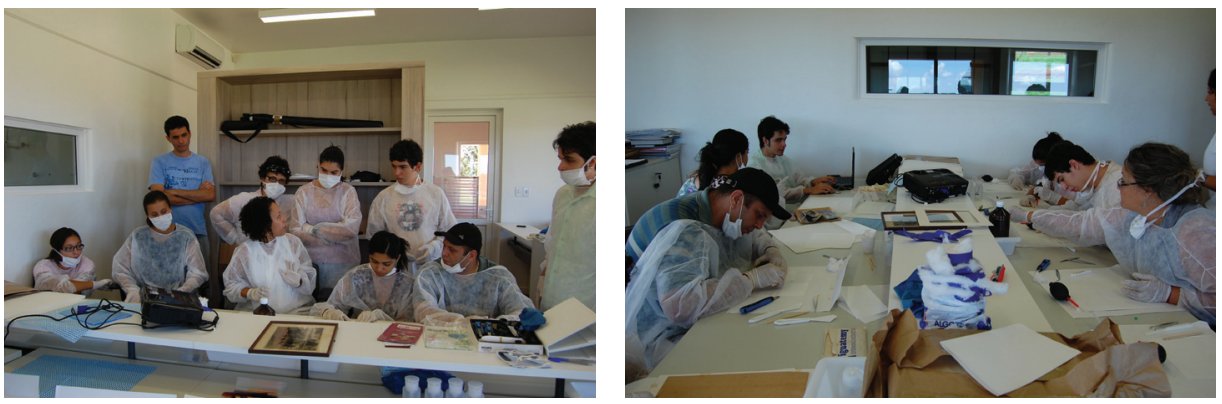

Na fase inicial da pesquisa, a partir da prática da leitura documental, os alunos identificaram os documentos, sensibilizaram-se com os conteúdos descritivos realizados, 
tanto dos proprietários sobre as instalações e demais produções da fazenda, quanto dos grafados pelos administradores nos casos específicos da cafeicultura, da ocorrência de tempestades, das pragas, dos falecimentos, dos registros ocasionais de instalação de novos colonos ou das fugas deles, das compras no armazém, dívidas ou pagamentos por pés de café. Uma particular visão do passado no cotidiano da época do café. Tais documentos recebiam atributos que qualificaram a informação do passado e, na atualidade, ainda podem ser identificados os elementos informacionais da vida no meio rural, da economia, da relação proprietário-colono e dos interesses voltados para o escoamento do café para a exportação.

Os livros de registros representam níveis de degradação das páginas sequenciais e podem comprometer a compreensão textual global. Denominamos estas formas manuscritas de microrresistências de informar, isto é, são elementos que possibilitam ao leitor reconhecer o que já não é mais possível ser vivenciado sobre a produção econômica, social e política do passado. As microrresistências se definem como a própria escrita, ou a imagem, a serem decodificadas nos suportes variados. São abundantes nos acervos brasileiros e nem sempre são previamente organizadas nos ambientes públicos ou privados. São informações realizadas pela escrita das canetas tinteiras, das máquinas datilográficas, da impressão mecânica dos jornais e revistas, pelas imagens fotográficas produzidas nas matrizes dos negativos em vidro, nitrato ou acetato, entre outros, assim como pelo som, isto é, das informações estruturadas.
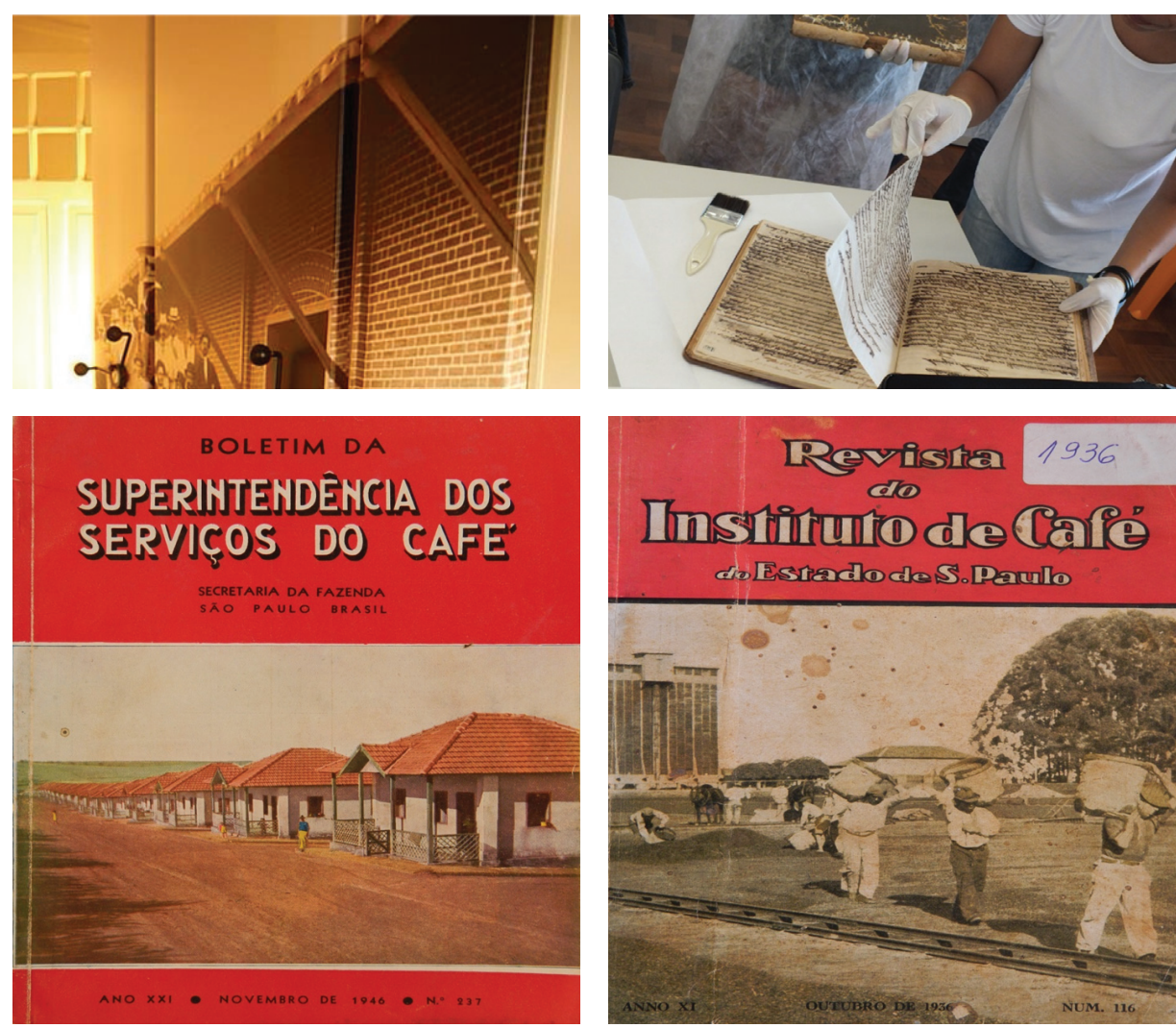

Figura 6 - Acervo armazenado em armário com trilhos deslizantes de fácil movimento (à esquerda). Documentos manuscritos sobre contabilidade da fazenda (à direita).

Figura 7 - Documentos digitalizados do acervo da fazenda Santa Cecília. Boletim da Superintendência dos Serviços do Café (1946) (à esquerda) e Revista do Instituto do Café do Estado de São Paulo (1936) (à direita). 


\section{PRODUÇÕES DE PESQUISA, CULTURA E EXTENSÃO}

Uma importante vertente de pesquisa a partir da implantação do Centro de Documentação foi envolver metodologias aplicadas à história oral, desenvolvidas pela pesquisadora Juliana Tiveron, aluna da pós-graduação de Psicologia da FFCLRP. Desta forma, o projeto intitulado A Memória da Comunidade Cafeicultora da Mogiana através de sua Oralidade constituiu um banco de histórias orais composto por cinco entrevistas com atores sociais do período cafeeiro da Mogiana. Vale mencionar que as gravações das entrevistas foram feitas em áudio (formato $\mathrm{WAV}$ e $\mathrm{MP}_{3}$ ), bem como transcritas e editadas, de modo a privilegiar as memórias referentes à produção do café, à ferrovia e sua atuação, à vida em colônia e à sede da fazenda. Tanto a gravação em áudio quanto o texto final passaram pela avaliação dos entrevistados e encontram-se disponíveis a futuras pesquisas. As entrevistas foram gravadas em dois DVDs e enviadas por correio a cada um dos entrevistados.

Diversos eventos de caráter científico, cultural e de extensão foram organizados pelos alunos. Assim, foram oferecidas nove oficinas, com carga horária de $16 \mathrm{~h}$, podendo ser repetidas com fins de continuidade e aprofundamento das práticas. São elas: História Oral (Profa. Dra. Daisy Perelmutter), Higienização e Embalagem de Documentos Históricos (Profa. Fernanda Brito), Apontamentos para conhecer a Cultura Visual do Café (Profa. Dra. Solange Ferraz de Lima, vice-diretora do Museu Paulista), Documentos Eletrônicos: Processos da Digitalização (Alex Ricardo Brasil, assistente de Arquivo Geral do Tribunal Eleitoral) e Formação de coleções de documentos impressos e manuscritos: registro, manuseio e protocolos de conservação (Rosaelena Scarpeline, diretora da biblioteca do Centro de Memória da Unicamp, e Profa. Dra. Luzia S. Fernandes, da UFSCar).

Palestras científicas foram também realizadas e ministradas: Preservação do Patrimônio Cultural: Alumínio - Metal - Tinta - Ferro (Prof. Dr. Augusto Neiva, da Escola Politécnica, da EP-USP) e Metodologias de conservação preventiva de documentos em suporte papel (Profa. Dra. Silvia Maria do Espírito Santo, da FFCLRP-USP). Um curso de longa duração: Indexação e Construção de Vocabulário Controlado (Profa. Dra. Maria Cristiane Barbosa Galvão, da FMRP-USP), que deverá dar continuidade ao projeto na criação de instrumento de pesquisa.

Selecionados alguns eventos científicos que pudessem adicionar questões reflexivas ao trabalho de pesquisa e extensão, houve aprovação de artigos para publicação em seus anais e participações, a partir de fevereiro de 2013, no Congresso Internacional do Conhecimento, na Universidade do Chile, com apresentação oral dos artigos A memória do café através de imagens fotográficas [6] e Memória visual do velho oeste paulista: Registro histórico e preservação do Patrimônio da vanguarda cafeeira [7]. Durante a International Federation for Latin American and Caribbean Studies, FIEALC, na Turquia, em outubro do mesmo ano, houve apresentação oral de um trabalho referente à atuação de dois alunos na análise das imagens fotográficas do Boletim da Superintendência do Café, com o artigo Memória visual do velho oeste paulista: Registro histórico e preservação do Patrimônio da vanguarda cafeeira. No I Congresso da Isko Portugal/Espanha, realizado na Universidade do Porto, Portugal, demonstramos os 
resultados de pesquisa no artigo Centralizar documentos digitais na história regional do café, publicado na Revista Prisma.Com em 2013 [8].

\section{Aplicação de Plano de Controle de Riscos}

Os alunos de Física Médica, além do estudo do maquinário do café [9], contribuíram com a identificação de riscos ao acervo com planejamento e controle de risco, que foram estruturados sistematicamente, considerando a ação de dez agentes de deterioração (forças físicas, criminosos, fogo, água, pestes, poluentes, luz/UV, temperatura incorreta, umidade relativa incorreta, dissociação) em seis diferentes níveis de "envoltórios" dos itens que compõem o acervo (região, sítio, edifício, sala, vitrine/ estante, embalagem/suporte) [10].

A análise ou quantificação da magnitude dos riscos foi feita a partir da quantificação da frequência ou velocidade em que se espera que o dano ocorra. Uma vez determinadas as magnitudes dos riscos para o acervo é possível compará-los e, juntamente com critérios complementares, estabelecer prioridades para seu tratamento e mitigação.

O desenvolvimento de opções para o tratamento de riscos também foi estruturado de forma sistemática, considerando-se cinco possíveis estágios de controle de riscos: evitar, bloquear, detectar, responder ao agente e recuperar o dano causado em cada um dos seis níveis de "envoltórios".

\section{Organização do Acervo do Centro de Documentação}

As coleções referentes à memória da região da Mogiana e do período cafeeiro pertencentes à fazenda Santa Cecília foram higienizadas, acondicionadas e digitalizadas. As coleções são: Sampaio Moreira (1890-1940) e Lauro D'Angelo, esta última da Casa de Cultura Rogério Cardoso de Mococa e parte do Fundo do Arquivo da Prefeitura Municipal de Cajuru. Estas coleções contêm documentos cartoriais, como registros de compra e venda de terras, livros de impostos (municipal e estadual), passaportes, contratos ou processos trabalhistas, livros ou documentos contábeis, fotografias, genealogias e periódicos.

\section{CONSIDERAÇÕES FINAIS}

O Centro de Documentação agrega possibilidades de pesquisa multidisciplinares na área de Humanidades e Exatas, entre outras referentes à história da tecnologia e cultura do período econômico cafeeiro de 1890 a 1940. A principal missão de um centro documental é conservar e disponibilizar conteúdos informacionais que são parte de um patrimônio.

Talvez, no final do processo da cadeia (ou fluxo) de tratamento documental, compreenda-se como a expressão cultural, artística e, consequentemente, a forma de pensar e sentir de uma comunidade em determinada época e lugar, foi sedimentando-se na história. São significações, saberes, técnicas, e podem se constituir em 
instrumentos de pesquisa. É também uma forma de preservar a memória do que somos e dar identidade aos povos. Entendendo as variantes da formação cultural, podemos vislumbrar transformações culturais e compreender as mudanças sociais que ocorrem no presente.

Dentro dessa questão, o papel do profissional da informação é fundamental, cabendo a ele colocar em prática a teoria, conceitos e métodos no veículo da memória coletiva: a identificação da documentação, conservação, tratamento e disseminação informacional. Os profissionais da informação podem, assim, interagir com estas instituições de memória e de pesquisa para que haja desenvolvimento das habilidades técnicas e teóricas. Os requisitos das áreas envolvem conceitos e práticas (como a criação de catálogos e índices), reconhecimento da memória, análise e o tratamento documental.

O projeto, ainda inconcluso, poderá ser aplicado em outros "pontos" institucionais de memória dos municípios da Região Administrativa de Ribeirão Preto, selecionados a partir do critério do convite e aceite dos profissionais da informação. $\mathrm{O}$ projeto poderá contribuir com pontos para reflexão do projeto pedagógico do curso em vigência e ênfases de Ciência da Informação na FFCLRP, considerando as questões de gestão na relação do poder público e privado, na perspectiva da documentação histórica.

O Centro de Documentação e Memória da Mogiana foi implantado com êxito e, além das atividades de tratamento de conservação de documentos do período cafeeiro, foi desenvolvida pesquisa, extensão universitária, envolvimento com a comunidade e também a análise dos documentos, com comparações teóricas e bibliográficas das linguagens adotadas para acesso documental. Foi fundamental para o sucesso do projeto o desenvolvimento, a observação e o acompanhamento das ações dos agentes - profissionais da informação -, necessárias para realizar proposições acadêmicas, isto é, organização de seminários, oficinas, encontros e visitas técnicas.

\section{REFERÊNCIAS}

[1] ABREU, M. de P.; LAGO, L. A. C. do. A economia brasileira no Império, 2001. Disponível em: <http://www.econ.puc-rio.br/pdf/td584.pdf.> Acesso em: 23 jan. 2014.

[2] FALEIROS, R. N. Fronteiras do Café: fazendeiros e "colonos" no interior paulista (1917-1937), 1 ed. Bauru-SP: EDUSC, p. 508, 2010.

[3] ARAUJO, F.A.N.G.. Digitalização e Preservação da Informação em meio digital: O caso do acervo memorial da Seca e do Semi-Árido da Universidade Federal do Rio Grande do Norte. 2013. 289p. Dissertação (Mestre em Ciência da Informação) - Faculdade de Engenharia, Universidade do Porto, Portugal, 2013.

[4] ESPÍRITO SANTO, S. M. Os "corredores do café" como mediação do objeto cognitivo para a Ciência da Informação, Rev. Ciência da Informação, Rio de Janeiro, v. 10, n. 4, 2009.

[5] Martins, A. L. Império do Café: a grande lavoura no Brasil 1850-1890, 7 ed. São Paulo: Atual, 1999.

[6] ESPÍRITO SANTO, S. M.; BALDO, J. C.; BENEDITO, M. A.; SANTOS, D. K. 
A memória do café através de imagens fotográficas. Disponível em: <http:// www.internacionaldelconocimiento.org/index.php?option=com_content\&vi ew $=$ section $\& i d=18 \&$ Itemid $=101>$. Acesso em: 27 jan. 2014 .

[7] ESPÍRITO SANTO, S. M.; DIAS, S. M. F.; GOMES, G. W. C. Memória visual do velho oeste paulista: Registro histórico e preservação do Patrimônio da vanguarda cafeeira. Disponível em: <http://www.internacionaldelconocimiento.org/index.php?option=com_content\&view=section\&id=18\&Item $\mathrm{id}=101>$. Acesso em: 27 jan. 2014.

[8] ESPÍRITO SANTO, S. M. Centralizar documentos digitais na história regional do café. Revista Prisma.Com, n. 20, 2013. Disponível em: <http://revistas. ua.pt/index.php/prismacom/>. Acesso em: 27 jan. 2014.

[9] LOBO, A. E. A.; KOVALSKI, H. M.; BARBOSA, J. H. O.; ESPÍRITO SANTO, S. M. Descrição dos processos físicos no beneficiamento do café no início do séc. XX. Disponível em: <http://uspdigital.usp.br/siicusp/cdOnli neTrabalhoObter? numeroInscricaoTrabalho $=1754$ \&numeroEdicao $=20 \&$ prin $\mathrm{t}=\mathrm{S}>$. Acesso em: 29 jan. 2014.

[10] PEDERSOLI Jr, J. L. Gerenciamento de riscos para o patrimônio cultural. São Paulo: Arquivo Histórico de São Paulo, 2011.

SILVIA MARIA DO ESPÍRITO SANTO doutora em Ciência da Informação e docente do Departamento de Educação, Informação e Comunicação da Faculdade de Filosofia, Ciências e Letras de Ribeirão Preto da Universidade de São Paulo (FFCLRP-USP) - e-mail: silesan@usp.br

JeAm haRoldo oliveira barbosa doutorando em Física Médica da Faculdade de Filosofia, Ciências e Letras de Ribeirão Preto da Universidade de São Paulo (FFCLRP-USP)

JULIANA DAL PONTe tIVERON mestranda em Psicologia da Faculdade de Filosofia, Ciências e Letras de Ribeirão Preto da Universidade de São Paulo (FFCLRP-USP) 